K. MICHALEK*\# K. GRYC*, L. SOCHA*, M. TKADLEČKOVÁ*, M. SATERNUS**,

J. PIEPRZYCA**, T. MERDER**, L. PINDOR***

\title{
PHYSICAL MODELLING OF TUNDISH SLAG ENTRAINMENT UNDER VARIOUS TECHNOLOGICAL CONDITIONS
}

\begin{abstract}
This paper deals with the issue of physical modelling of vortexes creation and tundish slag entrainment over the mouth of the nozzle into the individual casting strands. Proper physical model is equivalent to the operational continuous casting machine No. 2 in TŘINECKÉ ŽELEZÁRNY, a.s. Physical modelling methodology and simulated operational conditions are shortly described. Physical modelling was used for the evaluation of current conditions of steel casting at the application of different impact pads in the tundish. Further, laboratory measurement on the physical model aiming the determination of exact critical periods of vortexes creation and study of the slag entrainment as a consequence of changes in surface level during the tundish refilling to standard level were realised. The obtained results were analysed and discussed.

Keywords: steelmaking, tundish, slag entrainment, flow pattern, physical modelling
\end{abstract}

\section{Introduction}

Continuous casting machine (CCM) is inseparable part of the technology of steel production in the most modern metallurgical companies. The tundish is a technological node ensuring the continuous steel inflow to the mould, also at the time when ladles are exchanging on the stand.

It is necessary to realise the process of ladles exchange in appropriate way: the input of steel from the following heat (from the ladle) must be ensured before emptying the tundish where the steel of the previous heat is flowing out. Otherwise, there will be interruptions in the continuous casting process.

However, slag is present on the molten steel in the tundish. It plays the isolating role and partly also the refining role. Slag is also necessary to prevent from emptying the whole tundish as well as to prevent from the entrainment of the present slag into the individual casting strands. Slag entrainment through the nozzle into the mould can occur exactly at decreased critical level of steel in the tundish when vortex is created and as a consequence steel impurities can also be introduced into the mould. That is why, it is necessary to identify unequivocally such critical bath level and prevent its reduction and also creation of vortexes in the industry practice.

Physical modelling is commonly used for optimization the technology of steel and nonferrous metals production [1-6], therefore such modelling can be also used to determinate the critical level of steel bath in the tundish to prevent tundish slag from entrainment [7].
Many articles and authors [8-17] concentrated on such problem (slag entrainment in the metallurgical aggregates) using physical modelling with better or worse results. However, these works mainly focus on setting and adapting the theory of similarity for the case when liquids with various density and viscosity have to simulate steel and slag.

Results of such research [8-17] were discussed in details in article [18]. It can be stated that phenomena of slag entrainment and their risk of creating can be observed and studied the best when the similarity theory is based on Froude criterion:

$$
F r=\frac{\omega^{2}}{g \cdot l}
$$

where:

$\omega-$ the speed of liquid flow; $\mathrm{m} \cdot \mathrm{s}^{-1}$,

$g$ - gravitational acceleration; $\mathrm{m} \cdot \mathrm{s}^{-2}$,

$l$ - characteristic dimension; $\mathrm{m}$.

Many authors wanted to find the best combination of modelling liquids to fit the interactions between the slag and steel during steel draining process. Based on their findings [8-17] different systems of similarity were defined and used for their experiments.

The final decision concerning the physical modelling and its assumptions was made basing on work [14]. In this work the authors found that when the paraffin oil was applied, the critical level for vortex creation was at the height of $191 \mathrm{~mm}$, however when paraffin oil with low viscosity was used, then the height was $195 \mathrm{~mm}$. Assuming that experiments were realized without

\footnotetext{
VŠB-TECHNICAL UNIVERSITY OF OSTRAVA, FACULTY OF METALLURGY AND MATERIALS ENGINEERING, DEPARTMENT OF METALLURGY AND FOUNDRY AND REGIONAL MATERIALS SCIENCE AND TECHNOLOGY CENTRE, 17. LISTOPADU 15/2172, OSTRAVA-PORUBA, CZECH REPUBLIC

** SILESIAN UNIVERSITY OF TECHNOLOGY, FACULTY OF MATERIALS ENGINEERING AND METALLURGY, 8 KRASIŃSKIEGO STR, 40-019 KATOWICE, POLAND

*** TŘINECKÉ ŽELEZÁRNY, A.S., PRŮMYSLOVÁ 1000, TŘINEC-STARÉ MĚSTO, CZECH REPUBLIC

\# Corresponding author: karel.michalek@vsb.cz
} 
the second phase, only in the presence of atmosphere, the critical level of $200 \mathrm{~mm}$ for vortex creation was the highest.

Parameters such as viscosity and density of slag are very variable under real operational conditions in steel plants and are influenced by many continuously changing factors. Thus, they cannot be totally imitated or reflected by using of any combination of modelling liquids. Furthermore, it was shown that the highest critical levels are reached when the experiments are realized without the presence of liquids simulated slag. It is really important to determine the lower critical level of surface for the vortex creation in the tundish, thus in the real conditions it would be possible to prevent from such situation.

\section{Experimental methodology}

The main aim of this work was to determine the critical level of the steel bath for vortex creation in individual casting strands of tundish at units of continuous steel casting No. 2 (CCM2) located in Třinecké železárny, a.s.

Two tundishes, each with the nominal working weight $15 \mathrm{Mg}$ are symmetrical placed under the ladle with the nominal steel weight $180 \mathrm{Mg}$ placed in the casting strand. Fig. 1 shows the configuration of the tundishes in CCM2 and also the arrangement of shroud and each of eight casting strands, which are symmetrical.
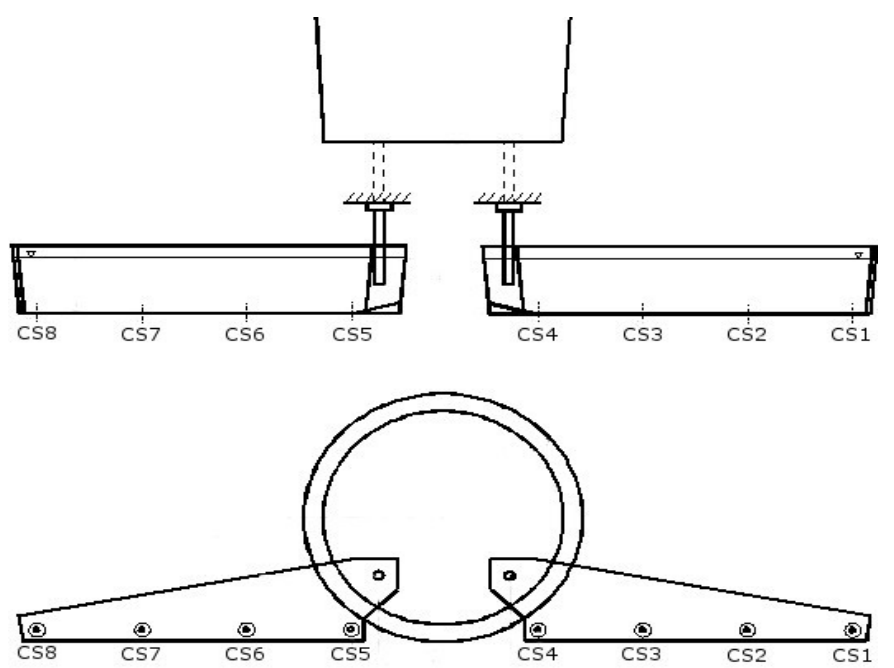

Fig. 1. Configuration of ladle and tundishes in CCM2 and view of shroud and each of eight casting strands

In the 1990th, physical model of tundish B (see Fig. 1 - left side) with casting strands 5 to 8 (CS5 to CS8) was built in the grounds of Třinecké železárny, a.s. This physical model was built in the geometrical scale $M_{l}=1: 3$. As the main criterion the Froude number Fr was used, in the form given in the equation (1). The correct assumption of the similarity system between the model and the real tundish was confirmed with the whole range of operationally verified experimental works focused on the study of character of casting in the tundish in order to optimize the range of intermixed zone [19] and the inner arrangement of tundishes [20].

Thus, to find the critical level of steel bath for the entrainment of tundish slag it was decided that research will be conducted in that tested and proved model.

According to the Trrinecké železárny, a.s. suggestions the previous work [18] was focused on studying the problem of slag entrainment risk during heat changes and for installation of different kind of impact pad. Based on the obtained results, casting speed $v=2.5 \mathrm{~m} \cdot \mathrm{min}^{-1}$ (model outflow for individual casting strand $=4 \mathrm{dm}^{3} \cdot \mathrm{min}^{-1}$ ) was selected.

Basing on literature findings and own experiences with methodological experiments, it was decided not to simulate two immiscible liquids. Instead of this for simulation of vortex development water was only used as a modelling liquid of steel. It was established that in this way relevant critical level of steel bath in the tundish should be determined after the recalculation to the conditions of the real tundish. Froude criterion Fr (1) was chosen as a governing criterion.

An aqueous solution of potassium permanganate $\left(\mathrm{KMnO}_{4}\right)$ was used for visualisation of vortex development above the individual nozzles entrances of casting strand. Two cameras were used for simultaneous recording of each experiment (Fig. 2).

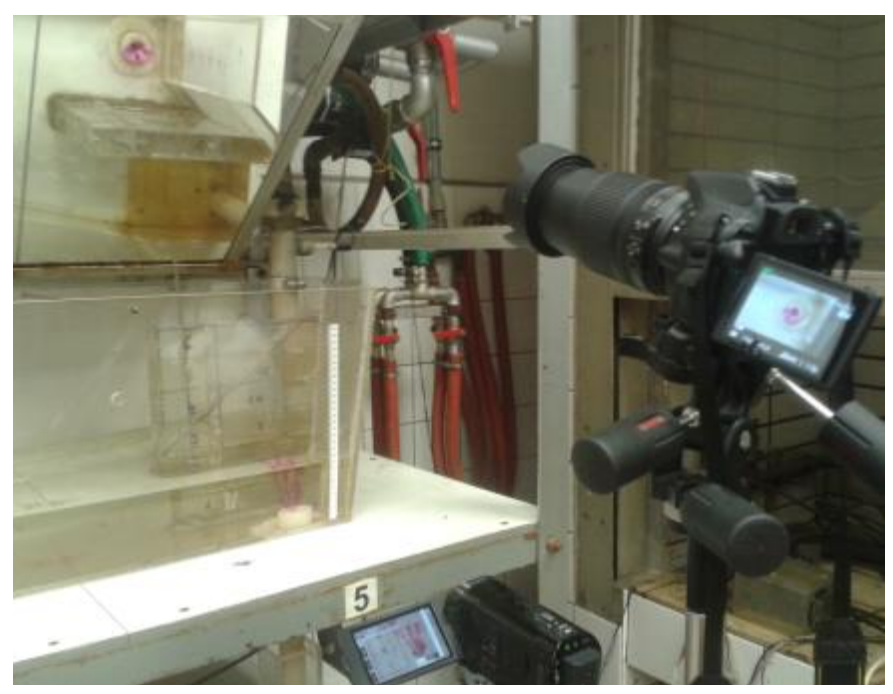

Fig. 2. Position of cameras used to observed phenomena occurring for casting strand No. 5 (physical model of CCM2 built in the geometrical scale $M_{l}=1: 3$ )

The first camera was zoomed in from the side of individual outlet (nozzle entrance), whereas the second was positioned to record the flow from the top view.

Each experiment started with filling through shroud the tundish up to the level of $18.2 \mathrm{~cm}(12 \mathrm{Mg}$ of steel in real tundish). Then, the inflow was stopped and emptying of tundish started - like in real conditions during changing the ladles - by defined outflow $\left(4 \mathrm{dm}^{3} \cdot \mathrm{min}^{-1}\right)$. Then the refilling with water from lower technological limit defined by equivalent of $6 \mathrm{Mg}$ of steel in tundish was started $(9.4 \mathrm{~cm}$ water level) to standard level $18.2 \mathrm{~cm}$ (12 Mg of steel in real tundish). 


\section{Results and discussion}

Based on such methodology, series of 24 experiments were carried out. For each cast strand and impact pad arrangement (old vs. new), three experiments were realised and recorded by two cameras as mentioned above. Records were analysed. Two steel levels (7.8 and 7.1 Mg) during steel draining and two others during refilling (7.8 and 9.1 Mg) were selected for discussion. Two types of flow into the outflow (Figs. 3,4 ) and other three typical flow types outside of the outlets (Figs. 5-7) were observed in the water volume near casting strands:

- flow into the casting strand:

$$
\text { - without rotation or }
$$$$
\text { - with rotation; }
$$

- flow outside the casting strand:

- with rotation;

- without rotation or

- with vertical rotation in the volume.

It is also necessary to mention that no developed vortexes were found during analysis of all records.

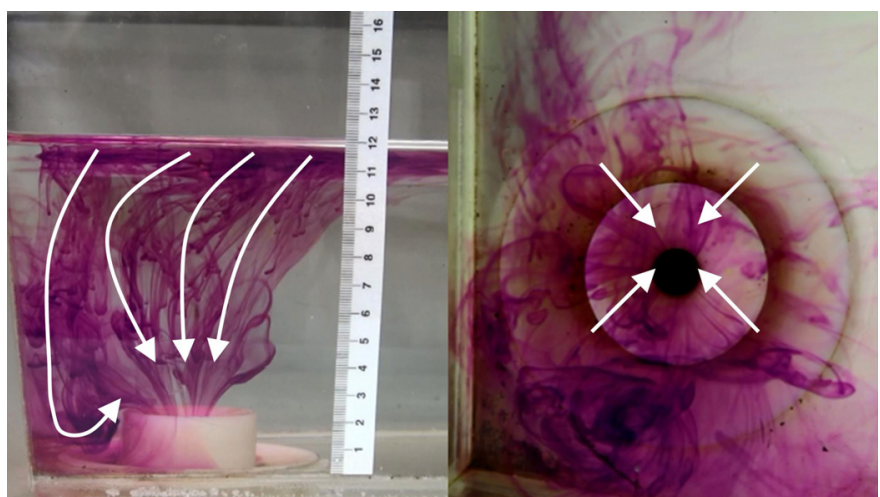

Fig. 3. Flow into the CS8 without rotation; new impact pad; $7.8 \mathrm{Mg}$ steel level; draining

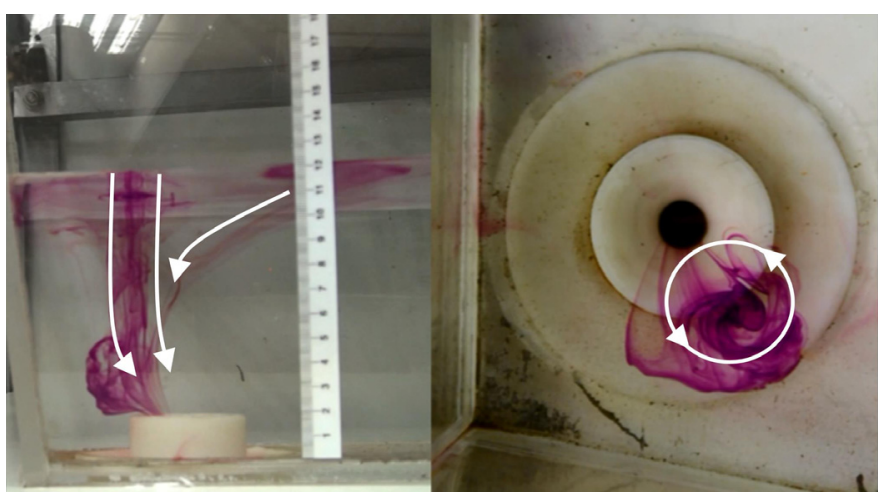

Fig. 4. Flow into the CS8 with rotation; old impact pad; $7.8 \mathrm{Mg}$ steel level; refilling

However, it was found that there are differences in the steel flow patterns between old impact area and new impact area design. Generally, it is obvious that new impact area design is created stronger piston flow into the tundish volume than previous impact area configuration (see Fig. 8).

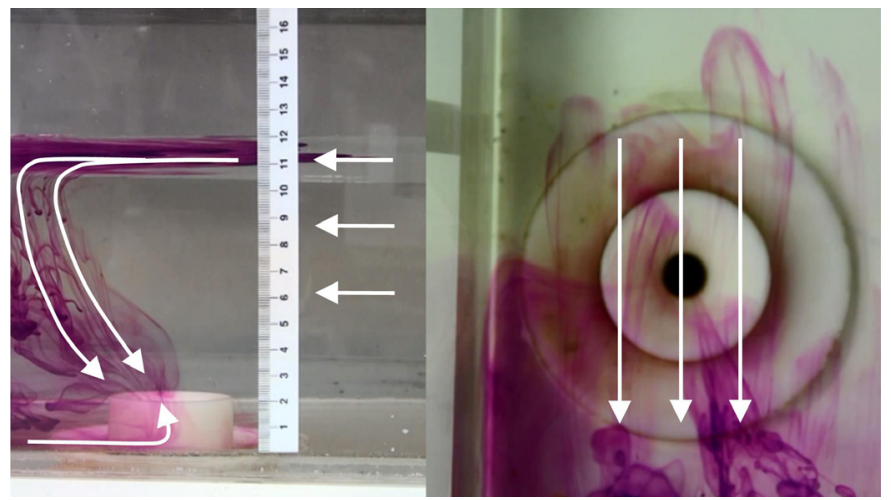

Fig. 5. Flow outside of the CS7 without rotation; new impact pad; 7.8 Mg steel level; refilling

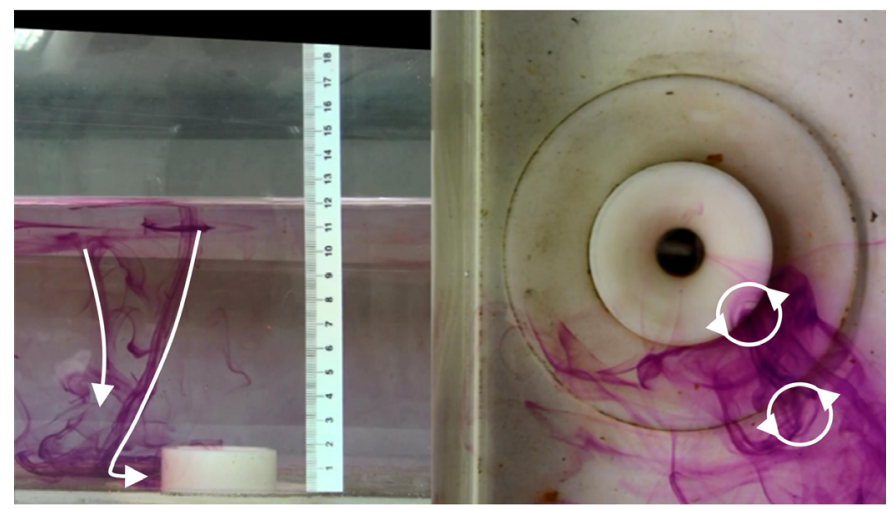

Fig. 6. Flow outside of the CS7 with rotation; old impact pad; $7.8 \mathrm{Mg}$ steel level; draining

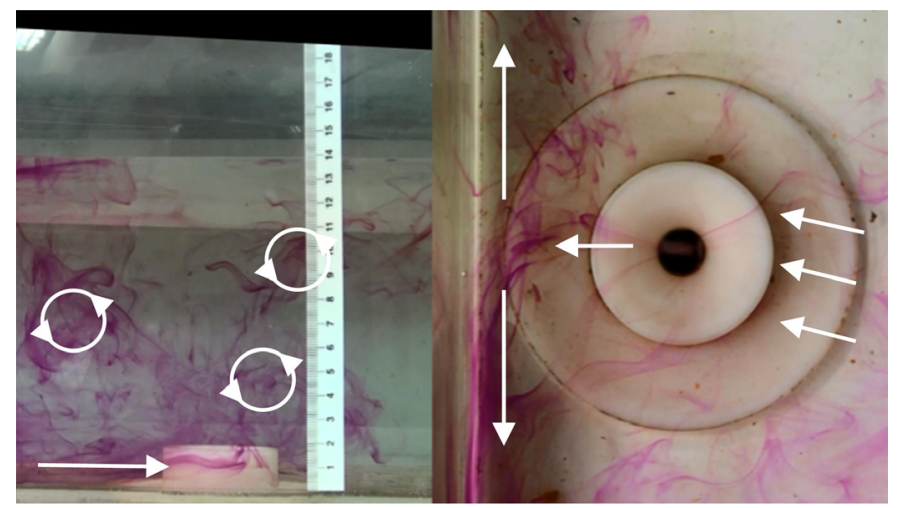

Fig. 7. Vertical rotation in the volume near CS7; old impact pad; $9.1 \mathrm{Mg}$ steel level; refilling

Moreover, these differences are visible not only during refilling. It looks that different impact pad configuration affects also steel flow during steel draining based on inertia of flow after previous casting process on the standard steel level (see Fig. 9).

\section{Conclusions}

This work presented the analysis of results of next stage research of complex study of tundish slag entrainment phe- 
a)

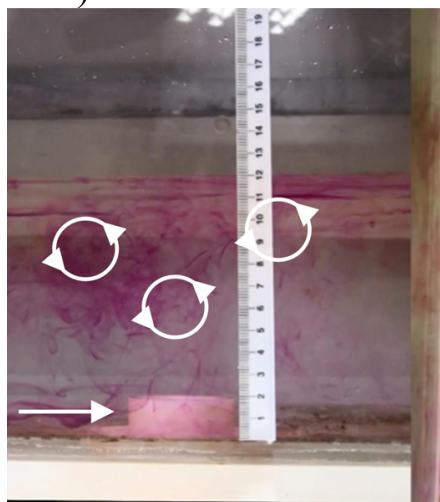

b)

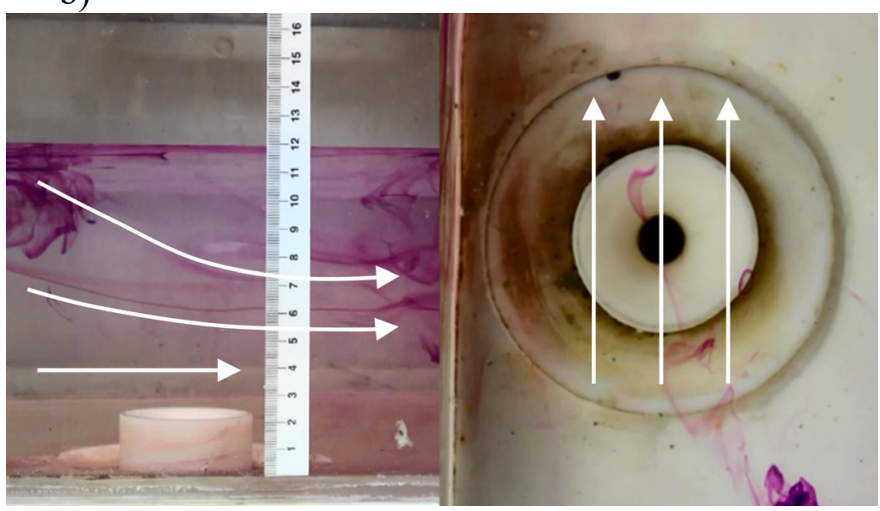

Fig. 8. Flow pattern during refilling process at $7.8 \mathrm{Mg}$ steel level for: a) old and b) new impact area design near CS6

nomena during continuous casting of steel at the CCM No. 2 in Třinecké železárny a. s. Presented physical modelling research was concerned to simulate the fluid flow pattern for draining and then for the refilling the steel during ladle changes.

The following conclusions were drawn:

1. Taking into account the theory of similarity, Froude criterion (1) was chosen as a governing criterion and slag entrainment was simulated only with the water representing steel without the top layer representing slag.

2. Five typical flow patterns were observed: flow into the casting strand without or with rotation; flow outside the casting strand with or without rotation and with vertical rotation in the volume.

3. No vortex formation was observed during analysis of all experiments. It indicates that assumption of the minimum bath level equalled $6 \mathrm{Mg}$ of steel in tundish is correct and safe especially taking into account the risk of tundish slag entrainment into the individual casting strands.

4. Change of impact area design caused the change of flow pattern. Due to lower number of areas with rotations it seems that new impact pad design generates bigger proportion of piston flow. On the other hand, this last finding should be confirmed by studying of residence time distribution in further works. a)

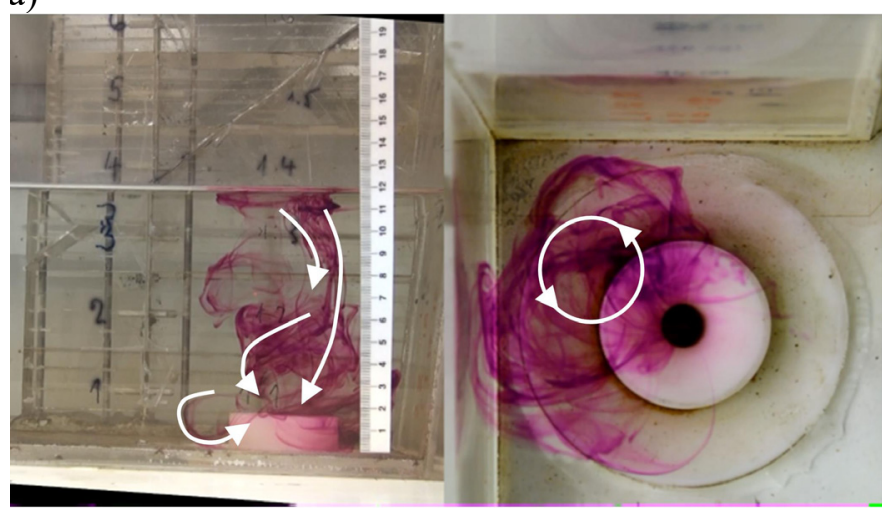

b)

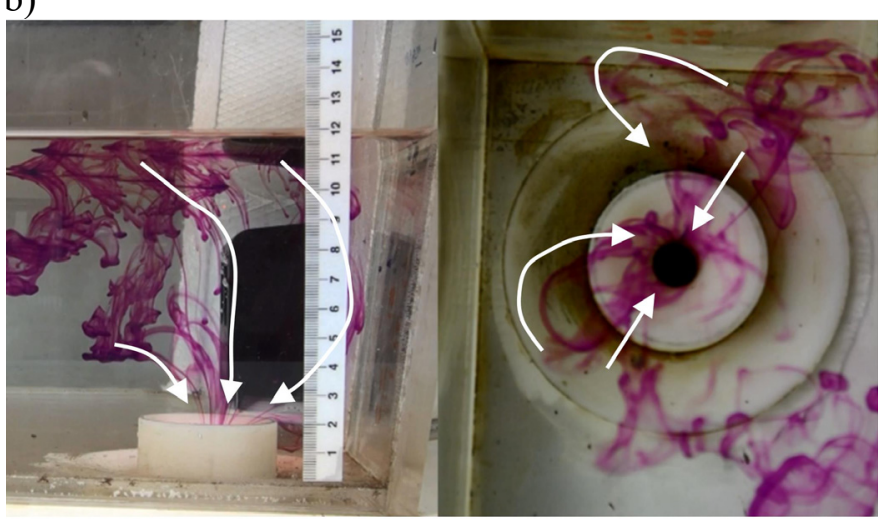

Fig. 9. Flow pattern during draining process at $7.8 \mathrm{Mg}$ steel level for: a) old and b) new impact area design near CS5

\section{Acknowledgement}

The work was carried out in the frame of project No. TA04010312 "Utilization of laser triangulation method with the aim of optimizing technology for surface quality improvement of steel intermediate products" solved with the financial support of TA CR.

This work was created with the support of projects of Student Grant Competition No.: SP2016/89, SP2016/103.

This paper was created in the Project No. LO1203 "Regional Materials Science and Technology Centre - Feasibility Program" funded by Ministry of Education, Youth and Sports of the Czech Republic.

This work was also supported by Polish Ministry for Science and Higher Education under internal grant BK264/RM2/2016 for Institute of Metals Technology, Silesian University of Technology, Poland.

\section{REFERENCES}

[1] K.M.Godiwalla, S.K. Sinha, C.S. Sivaramakrishnam, Steel Research Int. 65, 7, 267-271 (1994).

[2] S.C. Koria, S. Singh, ISIJ Int. 34, 10, 784-793 (1994).

[3] D. Mazumdar, R.I.L. Guthrie, ISIJ Int. 35, 1, 1-20 (1995).

[4] B. Li, F. Tsukihashi, ISIJ Int. 40, 12, 1203-1209 (2000).

[5] H.J. Odenthal, H. Pfeifer, M. Klaas, Steel Research Int. 71, 6-7, $210-220(2000)$ 
[6] A. Ruckert, M. Warzecha, R. Koitzsch, M. Pawlik, H. Pfeifer, Steel Research Int. 80, 8, 568-574 (2009).

[7] D. Mazumdar, J. W. Evans, Modelling of Steelmaking Processes. Boca Raton: CRC Press, 2010

[8] D. Mazumdar, O. P. Singh, J. Dutta, S. Ghost, D. Satish, S. Charakborty, Transactions of the Indian Institute of Metals. 64, 6, 593-605 (2011).

[9] G. Dharmendra, A.K. Lahiri, Metallurgical and Materials Transactions B 27B, 4, 695-697 (1996).

[10] D. Gupta, A.K. Lahiri, Metallurgical and Materials Transactions B 25B, 2, 227-233 (1994).

[11] R.W. Paul, F.T. Whitaker, The Relationship of Basic Tundish Powder Properties to Tundish Practises and Steel Quality. In Proceedings of Electric Furnance Conference Atlanta, USA 50, 197-206 (1992).

[12] R. Sankaranarayanan, R.I.L. Guthrie, Ironmaking and Steelmaking 29, 2, 147-153 (2002)
[13] G.M. Mazzaferro, M. Piva, S.P. Ferro, P. Bissio, M. Iglesias, A. Calvo, M.B. Goldschmit, Ironmaking and Steelmaking 31, 6, 1-6 (2004).

[14] R.D. Morales, O. Davila-Maldonado, I. Calderon, K. Morales-Higa, ISIJ Int. 53, 5, 782-791 (2013).

[15] D.R. Heaslip, Caster Steel Yield Improvement by Enhanced Ladle Bottom Design, Conference AISTech 2007, 127-134 (2007).

[16] S.C. Koria, U. Kanth, Steel Res. Int. 65, 1, 8-14 (1994).

[17] T. Merder, J. Pieprzyca, T. Saternus, Metalurgija 53, 2, 155-158 (2014).

[18] K. Michalek, K. Gryc, L. Socha, M. Tkadlečková, M. Saternus, J. Pieprzyca, T. Merder, Arch. Metall. Mater. 61, 1, 257-260 (2016).

[19] K. Michalek, K. Gryc, M. Tkadlečková, J. Morávka, T. Huczala, D. Bocek, D. Horáková, Materiali in Tehnologije 46, 6, 581-587 (2012).

[20] K. Gryc, K. Michalek, Z. Hudzieczek, M. Tkadlečková, Physical Modelling of Flow Pattern in 5-strand Asymmetrical Tundish with Baffles, Conference proceedings METAL 2010, 42-46 (2010). 